\title{
Treatment of Medial Canthal Tumor by Rotation Flap
}

\author{
Qirat Qurban', Zeeshan Kamil², Khalid Mahmood ${ }^{3}$ \\ ${ }^{1-3}$ Khalid Eye Clinic, Nazimabad, Karachi - Pakistan
}

\begin{abstract}
Purpose: To describe the cosmetic outcome after repairing medial canthal defects via glabellar rotation flaps in patients undergoing wide clear margin excision of medial canthal tumour.

Study Design: Interventional case series.

Place and Duration of Study: This study was conducted at Khalid Eye Clinic, Nazimabad, Karachi, from March 2019 to August 2019.

Methods: Eleven patients of both genders with clinically suspected medial canthal tumor were included in the study. Study approval was obtained from the Ethical Review Committee. Patients who underwent previous treatment such as radiation, cryotherapy or surgery were excluded. All surgeries were done to remove the tumor along with surrounding wide clear margins followed by reconstruction of the defect of the medial canthus area with the help of a rotation flap. Patients were followed for a period of up to six months post operatively for any wound related problems or recurrence. All patients were informed about the study and consent was obtained from each of them.

Results: All eleven patients of this study were satisfied at the end of the follow-up period with the final cosmetic outcome. Seven out of eleven patients were males and the remaining four were females, which also highlighted a greater incidence of medial canthal tumors in the male gender.

Conclusion: Glabellar rotation flap is a suitable procedure for the medial canthal area restoration after the tumor excision and can be customized as per the characteristics of the surrounding skin as well as the site, dimensions, and profundity of the defect.
\end{abstract}

Key Words: Medial canthal tumor, Glabellar rotation flap, Medial canthus.

How to Cite this Article: Qurban Q, Kamil Z, Mahmood K. Treatment of Medial Canthal Tumor by Rotation Flap. Pak J Ophthalmol. 2020; 36 (4): 360-364.

Doi: https://doi.org/10.36351/pjo.v36i4.1047

\section{INTRODUCTION}

Medial canthal region is often a favourable location for the development of malignant skin tumours, most commonly basal cell carcinoma, owing to an increased ultraviolet light exposure. ${ }^{1}$ Due to the presence of minimal skin and subcutaneous tissue at the multi-

Correspondence: Qirat Qurban

Khalid Eye Clinic, Nazimabad, Karachi-Pakistan

Email:qirat_89@hotmail.Com

Received: April 18, 2020

Accepted: July 29, 2020 contoured medial canthal region, tumor extension may involve the underlying structures such as orbicularis muscle, medial canthal ligament, periosteum along with lacrimal puncta and the eyelids, making reconstruction a challenge after the tumor is excised. ${ }^{2}$

Current surgical strategies for repairing and reconstructing medial canthal region defects incorporate direct closure, free dermal grafts and flaps. ${ }^{3}$ The surgical medial canthal region differs from the anatomical medial canthus in terms of size and extension since it lengthens perpendicularly into the region below the brow, to the nasal side close to the midline medially, and on top of the cheek inferiorly. ${ }^{4,5}$

Removal of the medial canthal tumour results in a 
cosmetically disfiguring defect. Hence, it is of utmost importance that a careful surgery is planned for adequate tumour excision and to reduce the functional and cosmetic consequences of surgery in order to restore the colour, continuity, consistency and depth of the dermal tissue for the maintenance of a more natural symmetrical external appearance. This is best done with the help of a flap contiguous to the defect such as glabellar flap transposition, which matches the tissue characteristics and maintains a good vascular supply important for the viability of the flap. ${ }^{6}$

This study aims at sharing our reconstructive strategy to provide an acceptable cosmetic outcome after repairing medial canthal defects via glabellar rotation flaps in patients undergoing wide clear margin excision of medial canthal tumours.

\section{METHODS}

This interventional case series was conducted at Khalid Eye Clinic, Nazimabad, Karachi, from March 2019 to August 2019 and included eleven patients of both genders with age ranging from 55 to 65 years, having clinically suspected medial canthal tumor. Surgical procedure was explained to the patients and informed consent was obtained. Study approval was obtained from the Ethical Review Committee. Each patient's data was collected and documented including demographic information, co-morbidities, size of the lesion, duration of the lesion, location of the lesion, size of the resulting defect, type of reconstructive surgery, eyelid opening, presence of eyelid deformity and aesthetic symmetry. Patients who underwent previous treatments such as radiation, cryotherapy or surgery were excluded from the study. Surgery was done under general anaesthesia. All surgeries were done to remove the medial canthal tumor along with surrounding wide clear margins and restoration of the medial canthus area with the help of a glabellar rotation flap by a single oculoplastic surgeon. Patients were followed for a period of up to six months post operatively and any recurrence, epiphora, wound related problems and cosmetic outcome was noted. All the postoperative follow-up and result of the surgery was assessed by another co-author.

After all aseptic measures, surgical site was marked by a sterile marker and suspected tumour along with wide clear margin (3-4 mm from the tumor edge) was excised and sent for histopathological analysis to validate the presence of margin clarity. The size, location, depth of the tissue deficiency and integrity of the lacrimal duct arrangement was assessed and glabellar rotation flap of adequate size was made on the adjacent area of the skin. Injection Bupivacaine $0.5 \%$ with $2 \%$ adrenaline was injected subcutaneously followed by physical pressure on the site of injection for 5 minutes to maintain hemostasis. The margins of the flap were incised using a scalpel followed by dissection with blunt scissors underneath the flap and transversely on the dorsum of the nose along the horizontally oriented relaxed skin tension lines. ${ }^{7}$ The flap was raised, mobilized and placed onto the defect. The proportion of flap to defect size was reserved at 3:1 to ensure a good supply of blood into the flap. The margins of the nasal skin were then sutured with interrupted $6-0$ Prolene and the lid skin was closed with 6-0 Vicryl sutures to develop the concavity of the medial canthal region. The area was double padded with ocular dressing to attain sufficient compression to prevent formation of hematomas and help to establish the shape of medial canthal region. Patients were called for follow-up for the removal of sutures following healing of the sutured skin margins. The results were classified as satisfactory if there was complete lid closure and unsatisfactory if there was any resultant exposure of the ocular surface. Topical antibiotic ointment and systemic antibiotic were prescribed twice daily for 7 days with digital pressing of the flap until removal of the sutures for a duration of minimum two months.

\section{RESULTS}

Mean age of the patients was $59.2 \pm 4.76$ years. Seven $(63.6 \%)$ patients were males and four $(36.3 \%)$ were females. At the end of the mean follow-up period of $185 \pm 11.3$ days, all patients of this study were satisfied with the cosmetic outcome with complete lid closure and formation of an acceptable medial canthal contour (Figure 1). During the course of follow-up, one $(9.09 \%)$ out of eleven patients developed pyrexia with slight inflammation of the flap which settled with oral antibiotic and antipyretics. Another patient (9.09\%) developed misdirection of lashes medially, which was treated by electrolysis. Three $(27.3 \%)$ out of the eleven patients, as a consequence of tumor excision, resulted in compromised lacrimal drainage system. Out of those three patients, one patient complained of watering and further treatment with Lester Jones dacryocystorhinostomy was planned. Rest of the patients did not develop any infection, 
bleeding, graft loss, necrosis, or reappearance of the tumor tissue throughout the duration of follow-up.

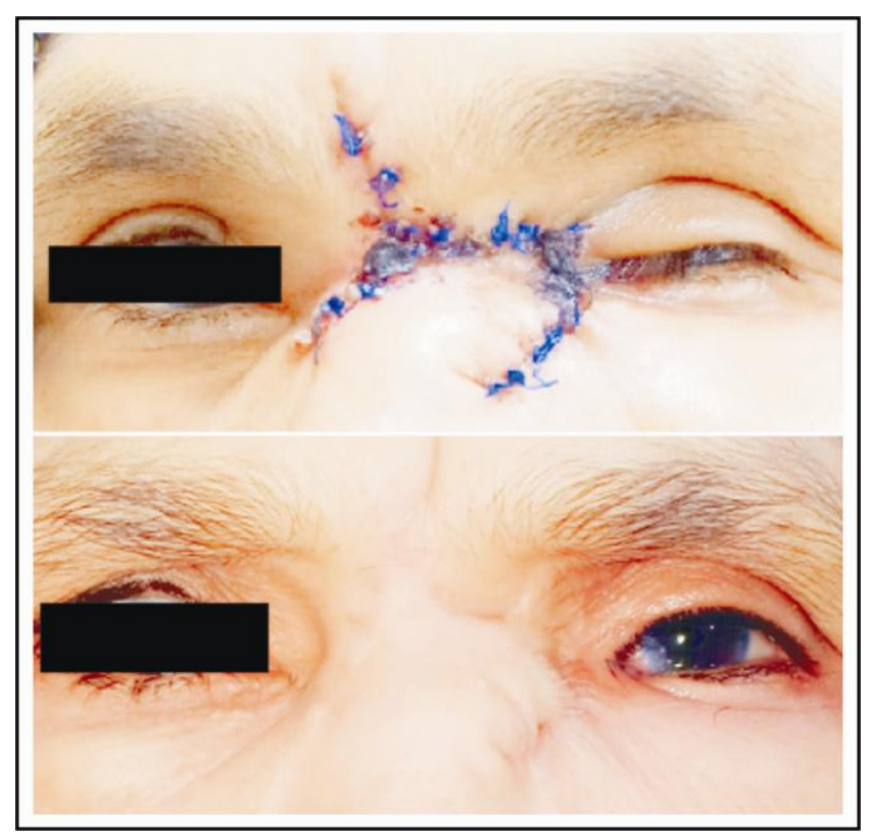

Picture 1: Immediate Post operative and at the End of Follow-up Period.

\section{DISCUSSION}

Malignant tumors of the eyelid constitute about $40 \%$ of all soft tissue tumors around the orbital region. ${ }^{8}$ In this part of the world, occurrence and conclusion of an assortment of tumors of the eyelid fluctuate considerably owing to the diverse geographical locations, hereditary backdrop, and social and financial standing of the affected patients. ${ }^{9}$ Risk factors such as chronic UV exposure, slow tumor growth, resemblance to benign lesions, along with unawareness, negligence to seek medical advice in time and lack of healthcare infrastructure are some of the reasons which result in delay in presentation and diagnosis.

When there is a clinical suspicion of a tumor at the medial canthus, the tumor as well as the surrounding tissue needs to be removed with wide clear margins to make sure that no cancer cells or tumor tissue is left behind. Reconstruction of full-thickness defects is complex if done in a single surgical procedure. Wide excision is followed by reconstruction of the medial canthal region. As a consequence of this surgical procedure, the conjunctiva, lacrimal puncta, canaliculi, caruncle, ligament of the medial canthus and the lacrimal sac may get sacrificed. ${ }^{10}$ There are various techniques available for the repair of medial canthal region including direct closure, flaps and grafts. No ideal procedure exists; therefore, each of the techniques has its own advantages and disadvantages. ${ }^{11}$

In 1993, Spinelli et al recommended that for the medial canthus restoration, local skin flap proved to be excellent. ${ }^{12}$ Another study by Onishi showed that for rebuilding of the medial canthal area, for deficit extending further ahead than the medial canthus onto the upper and lower eyelid's lateral side could be restored by rotating the apex of the glabellar flap. ${ }^{13}$ In this study we performed the glabellar rotation flap for the treatment of patients presenting with clinically suspected tumor of the medial canthal region after they underwent wide clear margin tumor excision. A surgeon ought to evaluate the depth, consistency and flexibility of the skin, underlying subcutaneous tissue, muscles, amount of the tissue to be rotated onto the defect and normal dermal tension lines while assessing a flap. ${ }^{10}$ The glabellar rotation flap comprises of a skin flap and underlying subcutaneous tissue that is transposed about a hinge position onto the neighboring medial canthal deficit. The idea behind selecting a rotation flap and not a free skin graft was due to the fact that, full-thickness skin graft may result in inadequate filling of defect volume, graft shrinkage leading to distortion, cosmetically unsatisfactory as compared to an adjacent flap, presence of color mismatch (hyperpigmentation or hypopigmentation with time) and necrosis from an impaired local blood supply. ${ }^{14}$ Flaps have their own blood supply, resulting in rapid healing with decreased risk of infection and necrosis, as well as a single operative site is required. Additional benefits of a glabellar rotation flap include a short operation time, less invasive with less obvious scarring as compared to a free skin graft. The cosmetic outcome is excellent since the ensuing blemish is concealed in a stress-free dermal tension line and becomes inconspicuous with time.

Like any surgical procedure, reconstruction using a rotation flap is not entirely free from complications. Some of the common problems which may be encountered subsequently include disparity in skin color, texture, poor eyelid motility, medial canthal concavity volume loss which may be cosmetically obvious, restricted globe motility from a cicatricial conjunctiva and constant watering, which possibly occurs as a consequence of inadequate corneal 
coverage, anomalous eyelid placement or injury to the nasolacrimal drainage structure. ${ }^{15}$

Sokol et al reported a greater preponderance of medial canthal tumour in the male gender, which was also found in present study. ${ }^{16}$ At the end of six months follow-up period in this study, all the patients were content with the cosmetic result having no inconvenience with the eyelid motility and complete lid closure. Misdirection of lashes medially was experienced by one patient $(9.09 \%)$, which was treated by electrolysis. Rafael et al noted ectropion in his study. ${ }^{17}$ Three $(27.3 \%)$ out of the eleven patients in this study, consequently resulted in compromised lacrimal drainage system. The raised skin caused by the flap pedicle passing the dorsum of the nasal area was not apparent and showed significant enhancement in the flap mass at follow-ups, tolerable to the patients since it was explained to each patient prior to the surgery. Lykoudis ${ }^{18}$ and Chao ${ }^{19}$ demonstrated the employment of glabellar flap and observed it to be straightforward, dependable and aesthetically acceptable for reconstruction of medial canthus deficits.

Timm A et al suggested that glabellar flap could be applied for the repair of defects measuring up to $30 \times 25 \mathrm{~mm} .{ }^{20}$ They also showed that this method was also appropriate for deeper defects in this area. The flap is also suitable if a patient has a recurrence of tumour.

Limitation of the study was small number of patients and only six months follow-up.

\section{CONCLUSION}

Glabellar rotation flap is a suitable method for the renovation of medial canthus area after the removal of tumor and can be customized according to the characteristics of the skin surrounding the orbit and the site, dimensions, and profundity of the deficit. It can be performed with good grace, has its own blood supply, is aesthetically pleasing owing to it following the dermal stresslines of the bridge of the nasal region and the glabellar region in addition to providing excellent skin shade, tissue depth and consistency match and does not necessitate asubsequent surgical process.

\section{Ethical Approval}

The study was approved by the Institutional review board/Ethical review board.

\section{Conflict of Interest}

Authors declared no conflict of interest.

\section{REFERENCES}

1. Lin HY, Cheng CY, Hsu WM, Kao WH, Chou P. Incidence of eyelid cancers in Taiwan: a 21-year review. Ophthalmology, 2006; 113: 2101-2107.

2. Chiarelli A, Forcignanb R, Boatto D, Zuliani E, Bisazza S. Reconstruction of the inner canthus region with a forehead muscle flap: a report on three cases. $\mathrm{Br}$ J Plast Surg. 2001; 54 (3): 248-252.

3. Bertelmann E, Rieck P, Guthoff R. Medial canthal reconstruction by a modified glabellar flap. Ophthalmologica. 2006; 220: 368-371.

4. Corredor-Osorio R. Rhomboid flap: An option to medial canthal reconstruction. Our Dermatol Online, 2017; 8: 329-332.

5. Maloof AJ, Leatherbarrow B. The glabellar flap dissected. Eye, 2000; 14: 597-605.

6. Akihiro O, Kiyoshi O, Emi O, Miho N. Medial canthal reconstruction with multiple local flaps. JPRAS Open, 2018; 15: 4-9.

7. Metha JS, Olver JM. Infra glabellar trans nasal bilobed flap in the reconstruction of medial canthal defects. Arch Ophthalmol. 2006; 124: 111-115.

8. Wójcicki P, Zachara M. Surgical Treatment of Eyelid Tumors. J Craniofac Surg. 2010; 21: 520-525.

9. Deprez M, Uffer S. Clinicopathological features of eyelid skin tumors. A retrospective study of 5504 cases and review of literature. Am J Dermatopathol. 2009; 31: 256-262.

10. Mustarde JC. Surgery of the medial canthus. In: Mustarde JC, editor. Repair and reconstruction in the orbital region. 3rd ed. Edinburgh: Churchill Livingstone; 1991: pp. 255-281.

11. Bertelmann E, Rieck P, Guthoff R. Medial canthal reconstruction by a modified glabellar flap. Ophthalmologica. 2006; 220: 368-371.

12. Spinelli HM, Jelks GW. Periocular reconstruction; a systemic approach. Plast Reconstr Surg. 1993; 91: 1017-1024.

13. Onishi K, Maruyama Y, Okada E, Ogino A. Medial canthal reconstruction with glabellar combined rintala flaps. Plast Reconstr Surg. 2007; 119: 537-541.

14. Collin JR. Eyelid reconstruction and tumour management. In: Collin JR. A Manual of Systematic Eyelid Surgery. 2nd ed. Edinburgh, Scotland: Churchill Livingstone; 1989: 73-74. 
15. Madge SN, Malhotra R, Thaller VT, Davis GJ, Kakizaki H, Mannor GE, et al. A systematic approach to the oculoplastic reconstruction of the eyelid medial canthal region after cancer excision. Int Ophthalmol Clin. 2009; 49 (4): 173-194.

16. Sokol I, Ina K, Erisa K. Choosing The Appropriate Reconstructive Technique for Eyelid Defects After Tumor Excision. J Surg Curr Trend Innov. 2019; 3: 023. DOI: $10.24966 /$ SCTI-7284/100023.

17. Rafael CO, Gabriela MCM, Gabriela BCV. The transnasal bilobed flap for medial canthal reconstruction. Heighpubs Otolaryngol and Rhinol. 2017; 1: 088-091. DOI: 10.29328/journal.hor.1001014.

18. Lykoudis EG, Lykoudis GE, Alexiou GA. "Pickaxe" double flap: A useful "tool" for reconstruction of deep large medial canthal defects-5-year experience and brief literature review. Aesth Plast Surg. 2015; 39: 410-413.
19. Chao Y, Xin X, Jiangping C. Medial canthal reconstruction with combined glabellar and orbicularis oculi myocutaneous advancement flaps. J Plast Reconstr Aesthet Surg. 2010; 63: 1624-1628.

20. Timm A, Vick H, Guthoff R. Glabellar transposition flap for medial canthal reconstruction after tumour excision. Klin Monatsbl Augenh, 2002; 219 (10): 740744.

\section{Authors' Designation and Contribution}

Qirat Qurban; Consultant Ophthalmologist: Data collection, Manuscript writer, final review.

Zeeshan Kamil; Consultant Ophthalmologist: Examiner, Manuscript writer, final review.

Khalid Mahmood; Consultant Ophthalmologist: Helped in data collection, final review. 